\title{
Shape-Controlled Nanoparticles from a Low-Energy Nanoemulsion
}

\author{
Manon Rolland," Nghia P. Truong," Kostas Parkatzidis, Emily H. Pilkington, Alexandre L. Torzynski, \\ Robert W. Style, Eric R. Dufresne, and Athina Anastasaki*
}

Cite This: JACS Au 2021, 1, 1975-1986

Read Online

ACCESS |

山lll Metrics \& More

回国 Article Recommendations

S1 Supporting Information

ABSTRACT: Nanoemulsion technology enables the production of uniform nanoparticles for a wide range of applications. However, existing nanoemulsion strategies are limited to the production of spherical nanoparticles. Here, we describe a low-energy nanoemulsion method to produce nanoparticles with various morphologies. By selecting a macroRAFT agent (poly(di(ethylene glycol) ethyl ether methacrylate-co-N-(2hydroxypropyl) methacrylamide) (P(DEGMA-co-HPMA $))$ that dramatically lowers the interfacial tension between monomer droplets and water, we can easily produce nanoemulsions at room temperature by manual shaking for a few seconds. With the addition of a common ionic surfactant (SDS), these nanoscale droplets are robustly stabilized at both the formation and elevated temperatures. Upon polymerization, we produce well-defined block copolymers forming nanoparticles with a wide range of controlled morphologies, including spheres, worm balls, worms, and vesicles. Our nanoemulsion polymerization is robust and well-controlled even without stirring or external deoxygenation. This method significantly expands the toolbox and availability of nanoemulsions and their tailor-made polymeric nanomaterials.

KEYWORDS: nanoparticles, nanoemulsion, miniemulsion, low energy, nanoparticle shape, RAFT polymerization, polymeric nanomaterials

\section{INTRODUCTION}

Nanoemulsions are kinetically stable dispersions of oil droplets in water with a typical size of between 20 and $500 \mathrm{~nm} .^{1-3}$ They have affected a number of fields ranging from drug delivery, 4,5 pharmaceuticals, and medical imaging ${ }^{6,7}$ to cosmetics, ${ }^{8,9}$ food, ${ }^{10,11}$ rheology, and polymer synthesis. ${ }^{12-14}$ A particularly exciting application is the combination of nanoemulsions with controlled radical polymerization strategies such as reversible addition-fragmentation chain-transfer (RAFT) polymerization. This paves the way for the synthesis of uniform nanoparticles and high-end-group-fidelity polymers. ${ }^{15-19}$ In comparison to traditional solution polymerization, compartmentalization and segregation within nanoscale droplets enable higher polymerization rates and require a much lower concentration of free radical initiator, thus significantly minimizing termination events. ${ }^{20-22}$ Furthermore, due to the increased stability and uniform size of nanoemulsions, the free transfer of monomer and propagating radicals between the droplets is suppressed. ${ }^{23}$ Since each droplet contains at least one propagating radical, all monomer droplets are converted into polymer nanoparticles, and the resulting particles have a size similar to that of the original monomer droplets (a 1:1 copy feature). ${ }^{23}$

Notwithstanding these unique advantages and properties, nanoemulsion polymerizations still suffer from two significant drawbacks that hinder their full potential. First, current nanoemulsion polymerizations can produce only nano- spheres. $^{24-27}$ This is a significant limitation, as the morphology has been demonstrated to determine both the properties and applications of nanoparticles. ${ }^{28,29}$ For instance, in comparison to nanospheres, nanoworms exhibit a longer circulation time, higher drug loading, enhanced photostability and catalytic efficiency, and faster diffusion of reagents to the core. ${ }^{30}$ On the other hand, vesicles or polymersomes can encapsulate both hydrophilic and hydrophobic drugs. ${ }^{31,32}$ Second, the vast majority of available nanoemulsion technologies require high mechanical energy to disperse the oily monomers and form small nanodroplets. ${ }^{33,34}$ However, high energy may degrade shear- and/or heat-sensitive monomers (e.g., prodrug monomers). ${ }^{4}$ In addition, in order to produce these intense and disruptive forces, highly specialized equipment is required such as high-pressure homogenizers, ultrasound generators, and high-shear stirrers. ${ }^{12,35}$ This equipment is not widely available to nonexperts, further complicating the polymerization setup, poses a high risk of metal contamination, and increases the overall costs, thus hindering the widespread use of nano-

Received: July 21, 2021

Published: October 1, 2021 


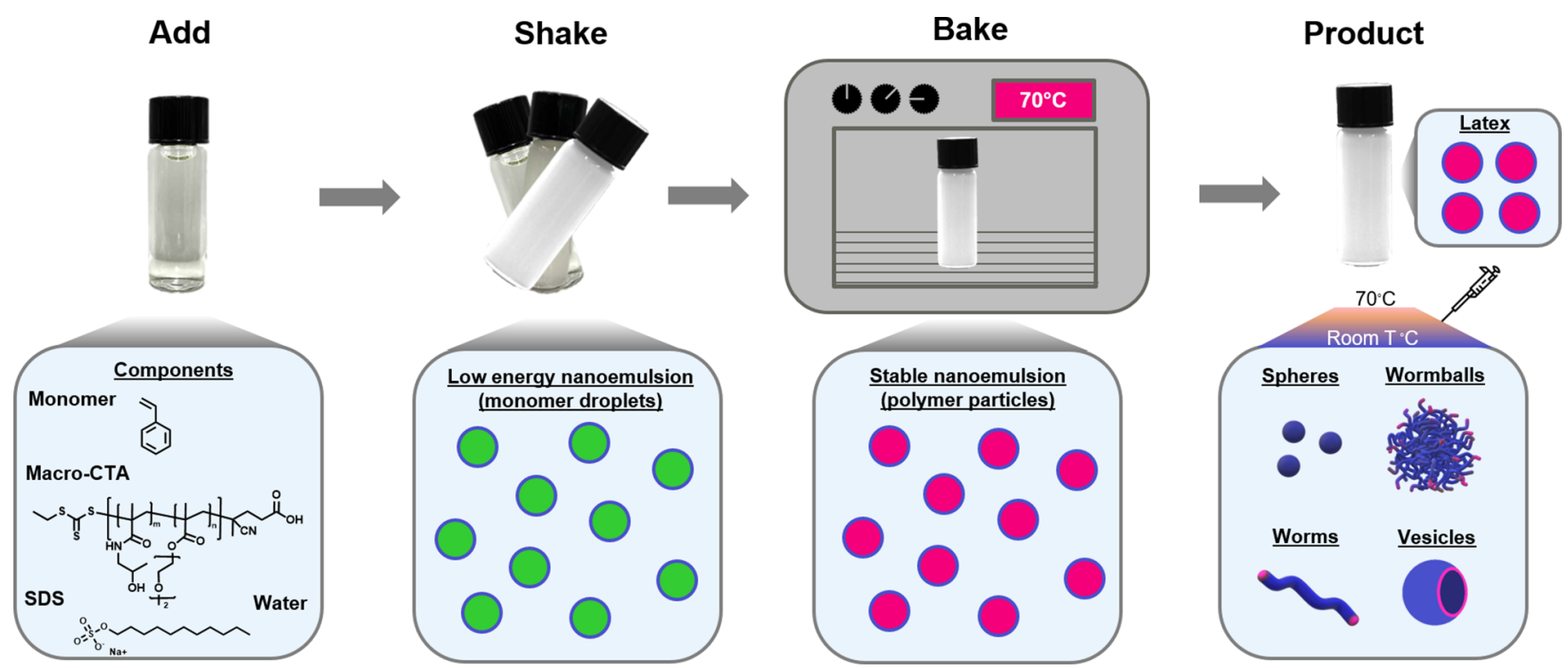

Figure 1. Schematic representation of the low-energy nanoemulsion. Azobis(isobutyronitrile), a hydrophobic radical initiator, was dissolved in the monomer for polymerization.

emulsions. ${ }^{4}$ As such, there is an urgent need to develop new methods that can prepare nanoemulsions without the need for a high-energy supply and, importantly, with the ability to obtain nanoparticles in different morphologies.

To this end, considerable efforts have been devoted to produce nanoemulsion via low-energy methods. ${ }^{2,36}$ For example, phase inversion composition ${ }^{37,38}$ is a widely used low-energy method in which the slow addition of water to an inverse water-in-oil macroemulsion reduces the emulsifier curvature and interfacial tension between water and the oil, thus decreasing the energy needed to generate nanoemulsion droplets. ${ }^{39}$ However, this method typically produces large and polydisperse nanoemulsion droplets. External stimuli, such as temperature, have also been exploited to induce a similar phase transition, although such stimuli may affect heat-sensitive compounds and restrict the available materials. ${ }^{40}$ Another popular method is to dilute an oil-in-water microemulsion containing thermodynamically stable oil droplets below $20 \mathrm{~nm}$. Key to this self-emulsification dilution method is the use of highly water soluble coemulsifiers or solvents that diffuse from the microemulsion droplet interface to the water phase during the water addition, thereby yielding nanoemulsion droplets. $^{41,42}$ This approach, however, is limited to specific microemulsion compositions and requires a large amount of organic solvents or coemulsifiers that are often toxic and incompatible with many applications. ${ }^{41}$ Most other low-energy nanoemulsion methods are also time-consuming and challenging to implement, require complex phase transitions or the use of additional components, and cannot be employed to produce nanoparticles with different morphologies such as nanoworms and nanovesicles. ${ }^{43-45}$ A simple low-energy method that can form nanoemulsions at room temperature and produce nanoparticles with different morphologies is highly desirable.

\section{RESULTS AND DISCUSSION}

\section{Low-Energy Method for the Production of Nanoemulsions at Room Temperature}

Here, we present a low-energy method that allows the formation of nanoparticles with complex morphologies (Figure
1). In particular, nanoemulsion droplets were formed at room temperature by mixing an oily monomer (styrene), water, and emulsifiers. Robust nanoemulsification was achieved through the synergistic combination of two compounds: (i) the smallmolecule surfactant sodium dodecyl sulfate (SDS) and (ii) a macromolecular chain transfer agent (macro-CTA or macroRAFT agent, poly(bis(ethylene glycol) ethyl ether methacrylate-co- $N$-(2-hydroxypropyl) methacrylamide) (P(DEGMA-coHPMA) $\left(M_{n}=8900\right.$; Figures S1 and S2 and Table S1). Upon shaking for $10 \mathrm{~s}$, a turbid white dispersion was formed, indicating the formation of nanodroplets. Dynamic light scattering (DLS) revealed a diameter of $180 \pm 13 \mathrm{~nm}$ (Table S2). When the vial was shaken for a shorter time (i.e., 2 s), slightly larger nanodroplets $(\sim 214 \mathrm{~nm})$ were formed. Instead, longer shaking times (i.e., $1 \mathrm{~min}$ ) resulted in nanodroplets with a similar size $(\sim 179 \mathrm{~nm}$, Table S3). The final nanodroplet size was independent of the method used to mix (manual shaking by hand or using a vortex/vibrator mixer, a magnetic stirrer, or a mechanical shaker). Therefore, the remainder of the experiments were conducted by manually shaking the vial to further simplify our approach and preclude the use of additional equipment and/or a stirring bar. Importantly, the observed size was within the nanoemulsion range $(20-500 \mathrm{~nm})$, and the nanodroplets remained stable at room temperature for at least 3 days (Figure S3). Phase separation was initiated on the fourth day and continued for 2 weeks. When the vial was shaken again, the nanoemulsion was re-formed (Figure S3 and Table S4). This suggests that our nanoemulsion droplets are kinetically stable but thermodynamically unstable, another typical characteristic of nanoemulsion systems.

\section{Mechanistic Investigation of the Low-Energy Method}

To reveal the mechanisms underlying this system exceptional ability to make stable nanoemulsions with low-energy mixing, we compared the surface tension and emulsion stability under a variety of conditions. Pure mixtures of oil and styrene cannot form an emulsion (Figure 2a). The surface tension of the bare oil/styrene interface, revealed by pendant drop tensiometry (Figure S4a), ${ }^{46}$ is about $32 \mathrm{mN} / \mathrm{m}$ (Figure 2e,g,h and Table $\mathrm{S} 5$ ). When SDS was added at $0.125 \mathrm{mg} / \mathrm{mL}$ (well below the 


\section{Formation of nanoemulsion (styrene*}

a. Water

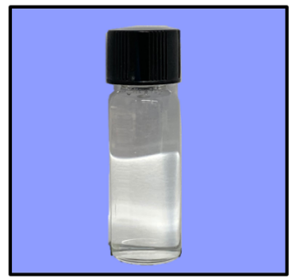

e. Water (W)

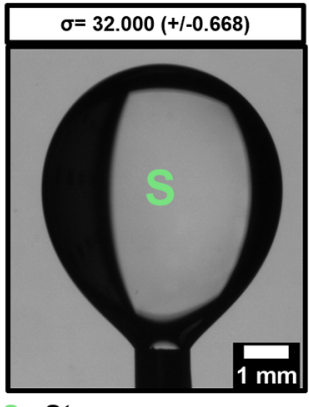

b. Water + SDS**

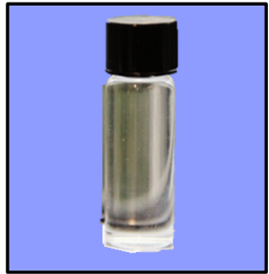

Inverse pendant drop method (styrene droplet)

f. Water + SDS **

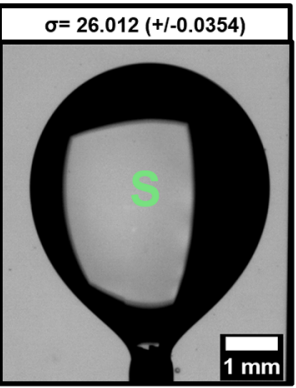

c. Water + Macro CTA ${ }^{* * *}$

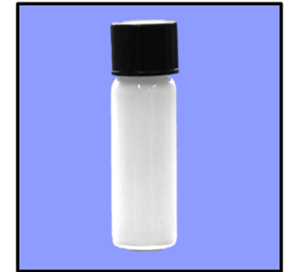

d. Water + SDS ${ }^{* *}+$ Macro CTA $^{* * *}$

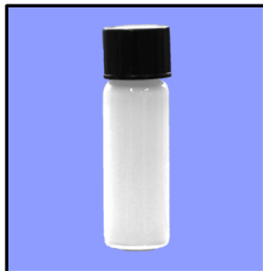

*17.5 $\mu \mathrm{L} / \mathrm{mL} \quad{ }^{* *} 0.125 \mathrm{mg} / \mathrm{mL} \quad{ }^{\star \star \star} 12.5 \mathrm{mg} / \mathrm{mL}$

\section{h. Water + SDS S $^{* *}$ Macro CTA $^{* * *}$}

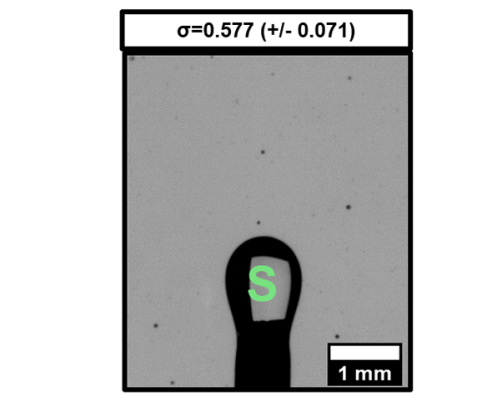

**0.125 mg/mL $\quad * * * 12.5 \mathrm{mg} / \mathrm{mL}$

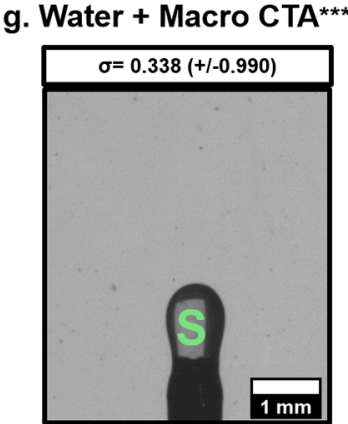

\section{Low energy nanoemulsion formation \& stabilization}

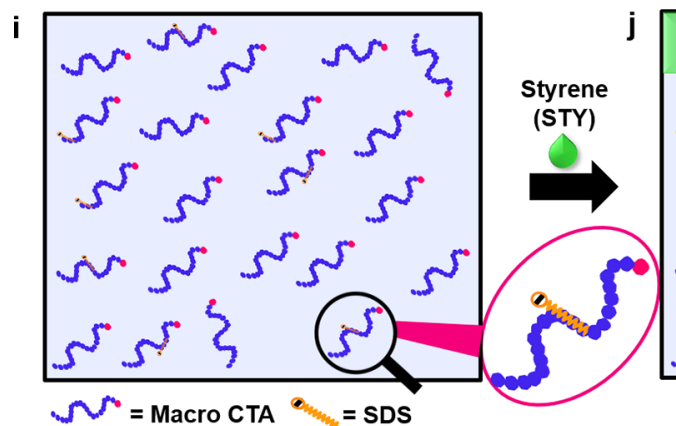

Figure 2. Visual representation of nanoemulsion formation upon shaking, surface tension measurements by the pendant drop method for a styrene droplet just about to detach (scale bar $1 \mathrm{~mm}$ ), and proposed mechanism of nanoemulsion formation by the low-energy method.

critical micelle concentration of SDS, $2.36 \mathrm{mg} / \mathrm{mL}){ }^{47}$ phase separation occurred immediately after shaking (Figure $2 \mathrm{~b}$ ) and the surface tension dropped slightly to $26 \mathrm{mN} / \mathrm{m}$ (Figure $2 \mathrm{f}$ ). While stable emulsions could be produced at higher concentrations (up to $12.5 \mathrm{mg} / \mathrm{mL}$ ), we could not reach the nanoemulsion regime with low-energy mixing (Figure S5). On the other hand, macro-CTA $(12.5 \mathrm{mg} / \mathrm{mL})$ enabled the formation of styrene nanodroplets, but they rapidly coarsened to diameters between 400 and $560 \mathrm{~nm}$ (Figure $2 \mathrm{c}$ and Table S6). When replacing the macro-CTA with a polymeric surfactant (Pluronic F108), nanoemulsion was not formed, although the interfacial tension was reduced to $9 \mathrm{mN} / \mathrm{m}$ (Figures S6-S7, Table S5). The macro-CTA had a dramatic effect on the surface tension, which was too low to be reliably measured using the pendant droplet method (Figure $2 \mathrm{~g}, \mathrm{~h}$ ). Instead, we measured the surface tension with the sessile droplet method (Figure S4b) ${ }^{48}$ and found an extremely low surface tension of $0.15 \mathrm{mN} / \mathrm{m}$ (Figure $\mathrm{S} 8$ and Table S7). Even though the macro-CTA/SDS combination yielded essentially the same surface tension (Figure S8 and Table S7), the size of the resulting droplet is much smaller $(180 \mathrm{~nm}$; Figure $2 \mathrm{~d}$ and Table S2).

We hypothesized that the hydrocarbon tail of SDS binds to the hydrocarbon backbone of the macro-CTA to form a strong emulsifier thanks to the negatively charged sulfate groups of SDS (Figure 2i,j). ${ }^{49}$ To evaluate this hypothesis, we measured the $\zeta$ potential of styrene droplets formed in the presence of the macro-CTA alone or macro-CTA and SDS. As expected, the $\zeta$ potential of the droplets stabilized by both the macroCTA and SDS was much higher $(-53 \mathrm{mV})$ than that without SDS (-20 mV, Table S8), indicating that SDS might contribute to the electrostatic stabilization of the nanoemulsion. This finding was further supported by the monovalent and divalent salt effect: a lower molar concentration of a divalent salt $\left(6.7 \mathrm{mM}\right.$ for $\left.\mathrm{CaCl}_{2}\right)$ was needed to destabilize the nanodroplets in comparison to that of a monovalent salt (25.3 $\mathrm{mM}$ for $\mathrm{NaCl}$, Table S9). The divalent salt reduced the Debye length and the repulsion between charged nanodroplets more in comparison to the monovalent salt, leading to the destabilization of nanodroplets at a lower concentration. This result suggests that the nanodroplets are 
a
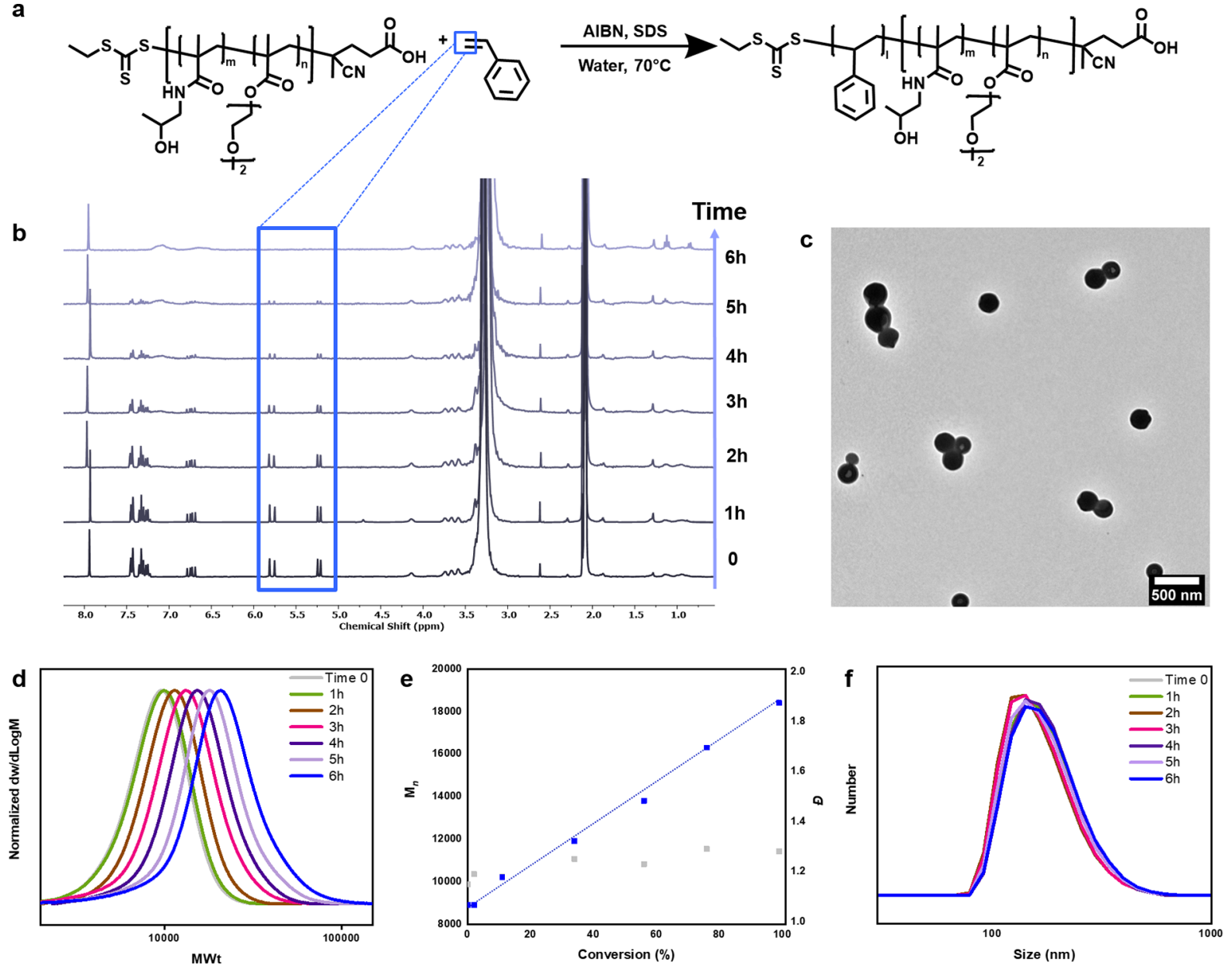

Figure 3. (a) Scheme of RAFT nanoemulsion polymerization of styrene. Kinetics and nanoparticle size tracking: (b) ${ }^{1} \mathrm{H}$ NMR spectra; (c) TEM image (scale bar $500 \mathrm{~nm}$ ); (d) SEC traces; (e) molecular weights and dispersities; (f) DLS size (by number).

stabilized via charge repulsion. ${ }^{50}$ Altogether, we discovered that the key to the formation of nanoemulsions by the present method is the synergistic combination of a macro-CTA, which dramatically reduces the surface tension to facilitate the formation of droplets, and a small-molecule surfactant that further stabilizes the droplets electrostatically.

The resulting nanoemulsions were stable not only at room temperature but also at 70,80 , and $90^{\circ} \mathrm{C}$. DLS confirmed that their size did not change at elevated temperatures, in contrast to the phase inversion temperature approach (PIT; Figure S9 and Table S10). ${ }^{51}$ When all of the components were combined without shaking, the solution remained macroscopically phase separated, with two transparent phases, ruling out spontaneous emulsification (Figure S10). Also, when macro-CTA was dissolved in styrene and SDS in water, mixing these two components led to rapid coarsening and creaming, although the interfacial tension was low $(<1 \mathrm{mN} / \mathrm{m}$, Figure $2 \mathrm{i}$ and Figures S11 and S12 and Tables S11 and S12). A similar phenomenon was found when both macro-CTA and SDS were mixed in the styrene phase, as we noticed that SDS does not dissolve well in styrene (Figure S11). Therefore, we propose that the macro-CTA and SDS complex before adsorbing to the oil/water (Figure 2i-k). In addition, comparable nanodroplet sizes were observed when the macro-CTA concentration was increased and decreased by 2 -fold (Table S13). We also found that, by increasing the SDS concentration, the droplet size was decreased (Figure S13 and Table S14).

\section{Application of Low-Energy Method to RAFT Polymerization}

Since the nanoemulsion produced by our low-energy method is stable at both room temperature and elevated temperature, it is an excellent candidate for droplet-localized controlled radical polymerization for the production of well-defined polymers and polymeric nanoparticles. To evaluate the compatibility of the present low-energy method with radical polymerization techniques, we conducted a RAFT polymerization. ${ }^{52-59}$ To a preformed aqueous solution containing both SDS and macroCTA, we added a hydrophobic monomer (i.e., styrene) in which a small amount of free radical initiator (AIBN) was previously dissolved. Upon shaking, DLS confirmed the formation of nanoemulsion droplets of size comparable to those formed in the absence of AIBN, thus indicating that the small amount of free radical initiator has no effect on the nanoemulsion size (Figure S14 and Table S15). It is noted that macro-CTA has a functional trithiocarbonate group attached at the chain end (Figure 3a), which allows it to also act as a macro-RAFT agent, thereby enabling the formation of a diblock copolymer after the polymerization.

We also sought to minimize the headspace in the reaction vessel by using a nearly full vial, thus limiting the amount of air within the vial. ${ }^{60-65}$ Without prior deoxygenation, the vial was sealed and placed in a preheated oven at $70{ }^{\circ} \mathrm{C}$ (Figure 1). After $6 \mathrm{~h}$, the polymerization was stopped by opening the vial to air. An analysis of the turbid white latex by nuclear magnetic 


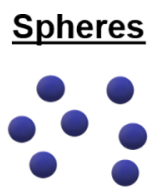

a

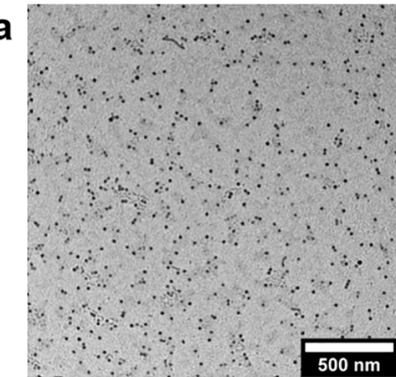

e

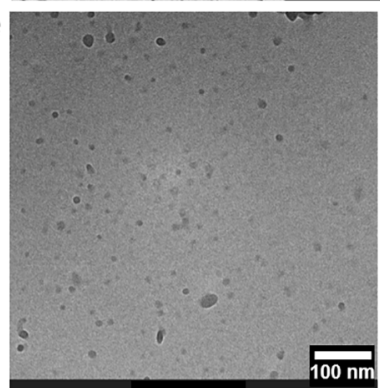

Wormballs

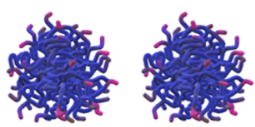

b

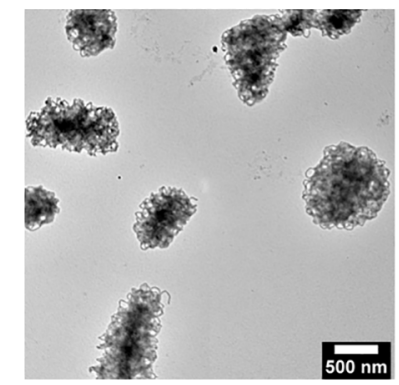

f

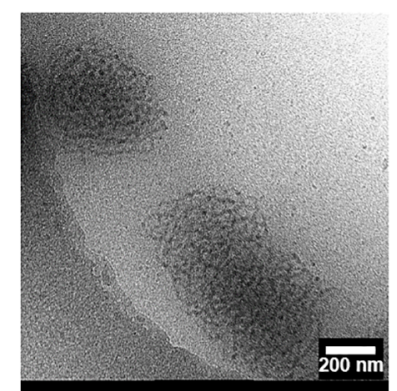

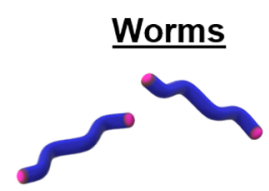

C

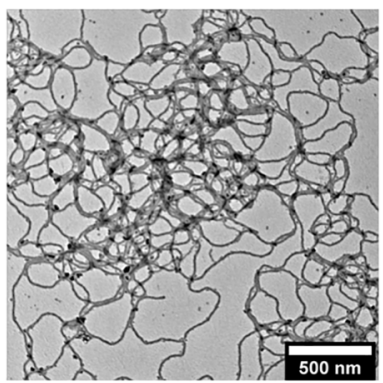

g

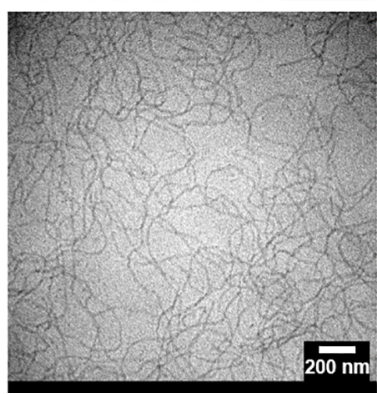

$\underline{\text { Vesicles }}$

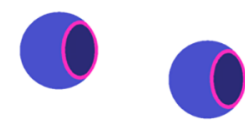

d

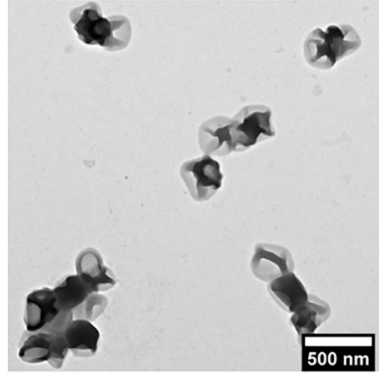

h

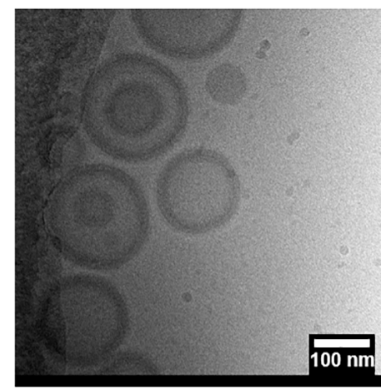

Figure 4. Morphologies of nanoparticles obtained after RAFT nanoemulsion polymerization: (a-d) TEM images (scale bar $500 \mathrm{~nm})$; (e-h) cryoEM images.

resonance (NMR) and size-exclusion chromatography (SEC) showed quantitative monomer conversion ( $\sim 99 \%$, Figure $3 \mathrm{~b}$ ) and a well-defined diblock copolymer shifting to higher molecular weights in comparison to that for the macro-CTA, with a relatively low dispersity $\left(\mathrm{M}_{n}=18400, Ð=1.28\right.$; Figure 3 and Table S16, entry 7). Importantly, the product of this RAFT nanoemulsion polymerization was not only a welldefined diblock copolymer but also relatively uniform nanospheres, a typical morphology of nanoemulsions (polydispersity $(\mathrm{PDI})=0.12$; Figure $3 \mathrm{c}$ and Table S16, entry 7). The transmission electron microscopy (TEM) image in Figure $3 \mathrm{c}$ also confirmed that the particle size of the nanoemulsion polymerization product (i.e., aggregates of polymer chains stabilized by SDS) was around $180 \mathrm{~nm}$, which is in agreement with DLS data (number distribution) and is in the range of nanoemulsion particles (Table S16). In the absence of SDS, the polymerization was still controlled but precipitation was observed after the polymerization (Figure S15 and Table S17). Pleasantly, with larger headspaces (up to $50 \%$ ), the polymerizations were successful, although a longer reaction time was required ( $8 \mathrm{~h}$; Figure S16 and Table S18). When the scale was increased 10-fold (i.e., $20 \mathrm{~mL}$ ), a nanoemulsion was also formed, followed by an efficient polymerization (Figure S19).

To further investigate this RAFT nanoemulsion polymerization, a detailed study of polymerization kinetics was performed alongside particle size tracking by DLS. To avoid the introduction of oxygen during sampling, five additional polymerization vials were prepared and placed in the oven. The vials were removed at different timeframes (i.e., one vial was removed every $1 \mathrm{~h}$ ) and analyzed by NMR, SEC, and DLS (Figure 3 and Table S16). In the first hour, no polymerization occurred (Table S16). This induction period was attributed to the consumption of dissolved oxygen by the initiator radicals.
Upon full oxygen consumption, the polymerization was expected to commence and proceed smoothly. Indeed, by an analysis of the subsequent vials, a linear increase in molecular weight with increasing conversion was observed, and the molecular weight distributions clearly shifted from lower to higher molecular weights (Figure 3). These data support a well-controlled RAFT nanoemulsion polymerization and suggest the formation of a diblock copolymer. Notably, the size profiles of the resulting nanoparticles were nearly identical with those of the starting monomer droplets and remained constant throughout the polymerization, highlighting the distinct 1:1 copy feature of an ideal nanoemulsion polymerization (Figure $3 \mathrm{f}$ and Table S16).

We performed two essential control reactions to highlight the importance of our nanoemulsion polymerization method. First, we attempted a polymerization without the prior formation of a nanoemulsion (i.e., just adding styrene on the top without shaking). The vial remained transparent after $6 \mathrm{~h}$ of heating at $70{ }^{\circ} \mathrm{C}$. An analysis of the solution by SEC showed no shift in molecular weight distribution (Figure S17 and Table S19), proving that the formation of a nanoemulsion is critical to a successful oxygen-tolerant RAFT polymerization. The compartmentalization effect (physical confinement of styrene into tiny spaces within nanoemulsion droplets) might reduce the amount of AIBN needed for oxygen consumption and polymerization, allowing the reaction to proceed with a low amount of radical initiator.

In the second control experiment, a magnetic stirring bar was placed in a vial containing all of the polymerization components also in the absence of prior shaking and heating. Upon heating and stirring at the same time in a preheated oil bath, large emulsion droplets were formed as the macro-CTA aggregated at high temperature, forming large emulsion 

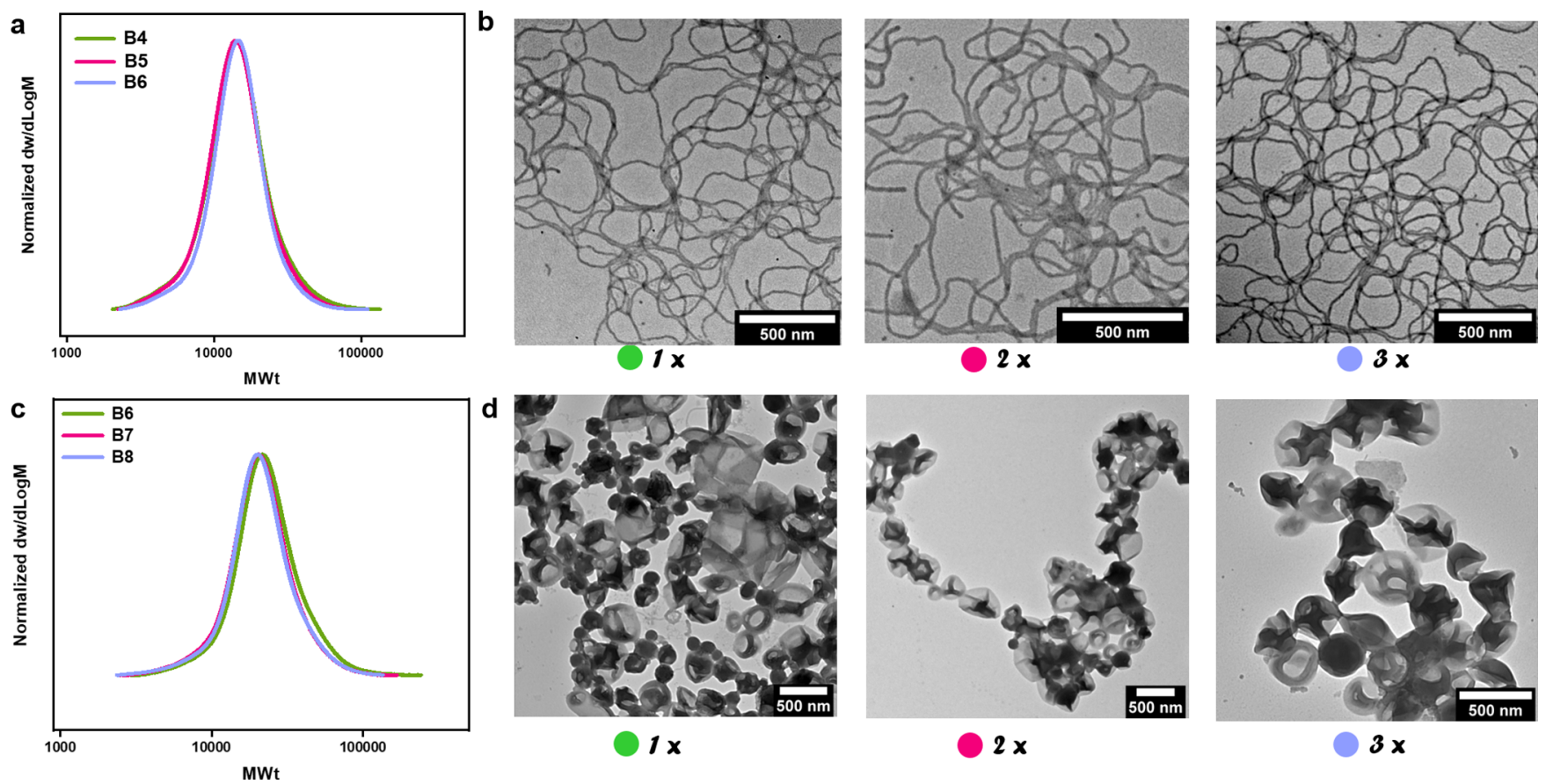

Figure 5. Reproducibility of RAFT nanoemulsion polymerization of styrene showing (a) SEC traces (B4-B6) and (b) TEM images (scale bars 500 $\mathrm{nm}$ ) of nanoworms and (c) SEC traces (B7-B9) and (d) TEM images (scale bars $500 \mathrm{~nm}$ ) of nanovesicles.

droplets (Table S20). In addition, an SEC analysis revealed two distinct molecular weight distributions and a very high dispersity $(\boxplus \approx 1.99)$, which indicates increased termination events (Figure S18). Collectively, the preformation of a nanoemulsion is essential for a controlled RAFT polymerization and allows for well-defined diblock copolymers exhibiting all the typical features of both a well-controlled radical polymerization and a nanoemulsion polymerization.

\section{Tailoring Morphology of Polymeric Nanoparticles}

Encouraged by these findings, we next explored potential avenues to tailor the morphology of nanoparticles synthesized by our low-energy nanoemulsion method. It is noted that, at high temperature, the formed diblock copolymer is hydrophobic with one block consisting of polystyrene and the second block being the thermoresponsive macro-CTA. However, at room temperature the thermoresponsive macroCTA is water-soluble, thus becoming the corona of the nanoparticles, while the PS block will form the core. To obtain nanoparticles with different shapes, we first varied the molecular weight of the polystyrene block by adding three different amounts of styrene prior to the start of polymerization (Table S21). In principle, changing the molecular weight of the hydrophobic block used for polymer selfassembly may lead to different morphologies due to an increase in the critical packing parameter, although such an effect has never been demonstrated for nanoemulsion particles. $^{66,67}$

All three polymerizations were allowed to commence for $6 \mathrm{~h}$, yielding well-defined block copolymers of different molecular weights while exhibiting low dispersity values and quantitative conversions (B1-B3, M $n=10800,12100,18300$, Figure S20 and Table S22). Prior to cooling of the nanoemulsion mixture, a small amount of toluene was added to the hot latexes to reduce the rigidity of the polystyrene block and aid in the morphological transformation ${ }^{68,69}$ (i.e., due to the high glass transition temperature of polystyrene, the polymer chains are rigid and, as such, without toluene, the particle morphology is trapped within the original nanoemulsion spheres). It should be noted that postaddition of toluene was not needed when the polymerization was stopped at low conversion, as unreacted styrene can also aid the morphology transformation (Figure S21 and Table S23). However, it is much more challenging to reproducibly obtain the same nanoparticle shape by targeting low conversions, as a small variation in polymerization conversion could result in a different shape, and therefore we recommend the toluene addition postpolymerization.

Significantly, by variation of the polystyrene molecular weight and optimization of the amount of added toluene, a wide range of morphologies could be obtained from nanoemulsion polymerization latexes, including nanospheres (micelles $\sim 10 \mathrm{~nm}$ ), worm balls, nanoworms, and nanovesicles (Figure $4 a-d$ ). Interestingly, the size of the nanovesicles was much smaller than that of previously synthesized vesicles from a traditional emulsion polymerization, most likely due to the smaller size of the original nanodroplets. It is noted that nanoworms could maintain their shape after $1 \mathrm{~h}$ of sonication (Figure S22). Also, we employed cryogenic electron microscopy (cryo-EM) to confirm that the nanoparticle shapes observed in their dry state are analogous to those found in the solution (Figure $4 \mathrm{e}-\mathrm{h}$ ).

It is important to note that the observed variation in morphologies is only possible thanks to the use of this special macro-CTA, which first reduces the interfacial tension, costabilizes the initial droplets, and subsequently allows for the synthesis of well-defined block copolymers and conversion to the nanoparticle's shell postpolymerization (Figures 1 and 2 ). It is highlighted that most, if not all, previously developed low-energy nanoemulsion methods employed small-molecule emulsifiers that were not covalently linked to the hydrophobic polymers after polymerization; as such, the possibility to obtain different morphologies was prohibited. To the best of our 
a

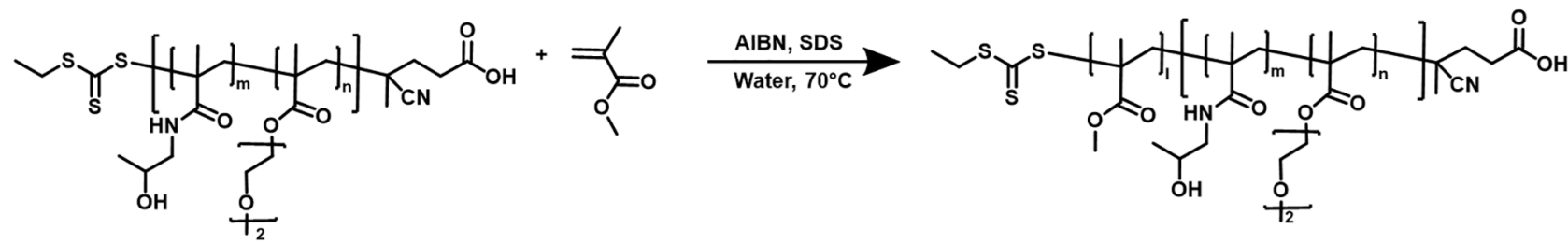

Spheres

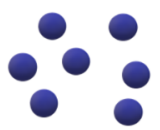

b

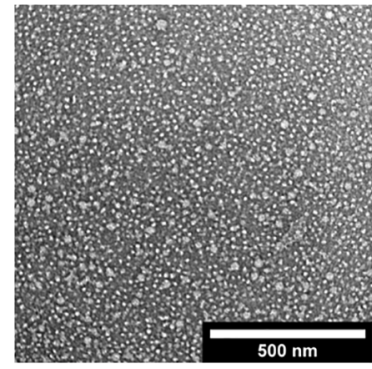

Wormballs

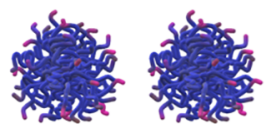

C

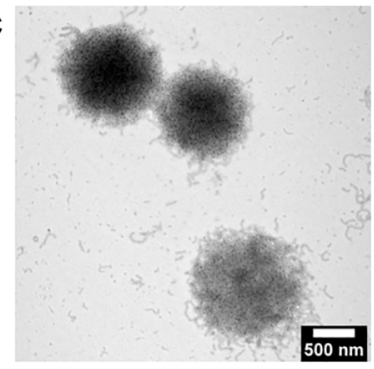

$\underline{\text { Worms }}$

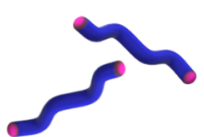

d

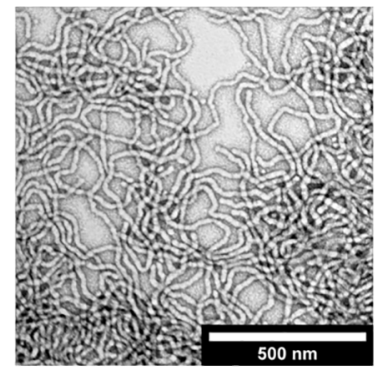

$\underline{\text { Vesicles }}$

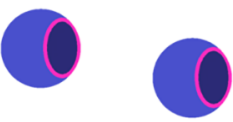

Figure 6. RAFT nanoemulsion polymerization of methyl methacrylate: (a) scheme and (b) morphologies illustrated by TEM images (scale bars $500 \mathrm{~nm})$.

knowledge, using a macro-RAFT agent to form nanoemulsions via a simple low-energy method while it also acts as a macroCTA during polymerization and as the corona of the resulting nanoparticles has not been previously reported, thus representing a significant step forward in emulsifier design and nanoemulsion technology.

To investigate the reproducibility of our method, we aimed at repeatedly generating high-ordered morphologies (i.e., nanoworms and nanovesicles). Reobtaining the rare wormlike morphology can be rather challenging, as even a minor variation in the molecular weight can disrupt this morphology. $^{70}$ Yet, three different polymerizations led to nearly identical molecular weight distributions and comparable wormlike morphologies (B4-B6; Figure 5a,b and Table S24), which highlights the reproducibility of the RAFT nanoemulsion polymerization and the morphological transformation. In addition, nanovesicles were also easily reobtained (B7-B9; Figure 5c,d and Table S25). This high reproducibility is attributed to the simplicity of the developed nanoemulsion method, the quantitative monomer conversion attained for each polymerization, and the facile morphological transformation. Many commonly employed methods that produce nanoworms or nanovesciles are often dependent on ceasing the polymerization at a specific monomer conversion, which is difficult to reproduce. Instead, this nanoemulsion polymerization method can achieve quantitative conversions, thus allowing for the reproducible formation of well-defined diblock copolymers with identical molecular weights and morphologies. We finally sought to expand the scope of polymeric materials synthesized and as such replaced styrene with methyl methacrylate (MMA). This is challenging to achieve by other methods such as PISA. The polymerization was reduced to $2 \mathrm{~h}$, as MMA has a faster propagation rate in comparison to styrene. Similar to polystyrene, PMMA nanoparticles with different morphologies could be obtained (B10-B12; Figure 6 and Figure S23 and Table S26), thus significantly expanding the scope and availability of tailor-made polymeric materials produced by our nanoemulsion formulation. Our nanoemulsion polymerization can also be applied to ethyl acrylate, demonstrating compatibility across multiple vinyl families (Figure S24 and Table S27). In comparison to well-known selfassembly methods such as polymerization-induced selfassembly (PISA), the preparation of shape-controlled nanoparticles using our approach operates through a new mechanism and offers distinct benefits such as interesting morphologies (e.g., worm balls) and the possibility to access spheres, worms, and vesicles of both styrenic and methacrylic moieties from the same macro-CTA.

\section{CONCLUSION}

We have introduced a simple low-energy method to produce nanoemulsions by simple shaking at room temperature. It is based on the synergistic effect of a macro-CTA, which dramatically lowers the interfacial tension, and SDS, which confers electrostatic stability. The nanoemulsion droplets can be produced without the need for additional toxic components, time-consuming dilution steps, special equipment, and change in temperature or $\mathrm{pH}$. In addition, the nanoemulsion is kinetically stable at both low and high temperatures, enabling the controlled radical polymerization of different hydrophobic monomer classes. Oxygen-tolerant RAFT nanoemulsion polymerization reached quantitative conversions without noticeable termination, resulting in the formation of welldefined diblock copolymers. Nanoparticles of different morphologies were also reproducibly obtained through nanoemulsion polymerizations. Key to our discovery is the use of a special macro-CTA that facilitates the formation of the initial nanoemulsion droplets by simply shaking, the successful RAFT polymerization of different monomer classes, and ultimately the formation of diblock copolymers yielding various nanoparticle morphologies. Therefore, this work not only significantly expands the toolbox of low-energy nanoemulsion but also creates new opportunities for a myriad of 
applications in which the nanoparticle morphology plays a vital role.

\section{EXPERIMENTAL SECTION}

Material information and instrumentations are detailed in the Supporting Information.

Synthesis of $\mathrm{P}(\mathrm{DEGMA}-\mathrm{CO}-\mathrm{HPMA})-\mathrm{SC}(=\mathrm{S}) \mathrm{SC}_{2} \mathrm{H}_{5}$ Utilized as a Macro-Chain Transfer Agent (macro-CTA)

DEGMA ( 3.5 g, $0.0186 \mathrm{~mol}, 40$ equiv), ECT ( $122.6 \mathrm{mg}, 0.0005 \mathrm{~mol}$, 1 equiv), HPMA ( $1.33 \mathrm{~g}, 0.0093 \mathrm{~mol}, 20$ equiv), and ACPA (10.5 mg, $0.0004 \mathrm{~mol}, 0.1$ equiv) were dissolved in DMSO $(20 \mathrm{~mL})$ and placed in a $25 \mathrm{~mL}$ round-bottom flask. After the flask was closed with a septum, the solution was degassed with nitrogen for $1 \mathrm{~h}$ and placed in a preheated oil bath $\left(70^{\circ} \mathrm{C}\right)$ at $300 \mathrm{rpm}$. After $8.5 \mathrm{~h}$, the reaction mixture was cooled in an ice bath, exposed to air, and sampled to determine the DEGMA and HPMA conversion by ${ }^{1} \mathrm{H}$ NMR. The solution was then dialyzed against acetone $(500 \mathrm{~mL})$ for $1 \mathrm{~h}$ to remove DMSO from the solution. Then, the solution was precipitated in a mixture of petroleum ether and diethyl ether $(1 / 1, \mathrm{v} / \mathrm{v})$, isolated by centrifugation, and redissolved in acetone. This step was repeated three times to remove unreacted monomers. The product was dried in a vacuum oven for $48 \mathrm{~h}$ and analyzed by SEC and ${ }^{1} \mathrm{H}$ NMR. The conversion of DEGMA was calculated by the integral area of a peak at $6.0 \mathrm{ppm}\left(I_{6.0}\right)$ and a peak in the range $3.8-4.3 \mathrm{ppm}\left(I_{3.8-4.3}\right)$ using the following equation: conversion of DEGMA $=100 \times\left[1-\left(2 \times I_{6.0} /\right.\right.$ $\left.I_{3.8-4.3}\right)$ ]. The conversion of HPMA was calculated by the integral area of a peak at $5.3 \mathrm{ppm}\left(I_{5.3}\right)$ and a peak in the range 4.6-4.7 ppm $\left(I_{4.5-4.8}\right)$ using the following equation: conversion of HPMA $=100 \times$ $\left[1-\left(I_{5.3} / I_{4.5}-4.8\right)\right]$.

Formation of Styrene Nanoemulsion by Simple Shaking, Vortexing, Stirring, or Using a Mechanical Shaker and Stability Study

macro-CTA ( $25 \mathrm{mg}, 0.0028 \mathrm{mmol}$ ) was l,aced in a $2 \mathrm{~mL}$ glass vial and was dissolved with an aqueous solution of SDS $(0.25 \mathrm{mg}$ of SDS in 2 $\mathrm{mL}$ of deionized water, $0.0009 \mathrm{mmol})$. Then, styrene $(35 \mu \mathrm{L}, 0.3045$ $\mathrm{mmol}$ ) was added on the top of the SDS and macro-CTA solution. The vial was capped and then shaken by hand, vortexed (speed 10), stirred (speed $300 \mathrm{rpm}$ ) or shaken using a mechanical shaker (speed $300 \mathrm{rpm}$ ) for $10 \mathrm{~s}$. To compare, the vial was also shaken by hand for 2 $\mathrm{s}$ and $1 \mathrm{~min}$. The resulting latexes were analyzed by DLS to determine the particle size and polydispersity. Additionally, the vial shaken by hand for $10 \mathrm{~s}$ was left on the bench at room temperature for 13 days without touching and photos were taken regularly to monitor the phase separation. Finally, after 13 days, the vial was shaken again and DLS was used to determine the particle size.

Inverse Pendant Drop and Sessile Drop Measurements to Obtain Interfacial Tension Values

As illustrated in Figure S4, a stabilized droplet is illuminated by an external light source and imaged through telecentric lens. For each measurement of the interfacial tension, a series of 10 different droplets were imaged and analyzed through MATLAB ${ }^{48}$ codes, where the droplet contour is detected and fitted to its theoretical shape. It is noted that, for the inverse pendant drop method, pictures were taken upside down and flipped before analyzing with the MATLAB code.

\section{$\zeta$ Potential Measurement}

macro-CTA (25 mg, $0.0028 \mathrm{mmol}$ ) was placed in a $2 \mathrm{~mL}$ glass vial and was dissolved with an aqueous solution of SDS (0.25 mg of SDS in $2 \mathrm{~mL}$ of deionized water, $0.0009 \mathrm{mmol})$. Then, styrene $(35 \mu \mathrm{L}$, $0.3045 \mathrm{mmol}$ ) was added on the top of the SDS and macro-CTA solution. The vial was capped and then shaken by hand. The resulting latex was dissolved 10 times with deionized water and analyzed by DLS to determine the $\zeta$ potential. The same procedure was repeated by excluding SDS (i.e., only macro-CTA and styrene).
Screening of Particle Charges by Subsequent Addition of $\mathrm{NaCl}$ and $\mathrm{CaCl}_{2}$ Salts

macro-CTA $(25 \mathrm{mg}, 0.0028 \mathrm{mmol})$ was placed in a $2 \mathrm{~mL}$ glass vial and was dissolved with an aqueous solution of SDS (0.25 mg of SDS in $2 \mathrm{~mL}$ of deionized water, $0.0009 \mathrm{mmol})$. Then, styrene $(35 \mu \mathrm{L}$, $0.3045 \mathrm{mmol}$ ) was added on the top of the SDS and macro-CTA solution. The vial was capped and then shaken by hand, resulting in a white latex. In parallel, a stock solution of $\mathrm{NaCl}$ dissolved in deionized water $(100 \mathrm{mg} / \mathrm{mL}, 1.7 \mathrm{M})$ was prepared. This solution was gradually added $(1 \mu \mathrm{L}(0.1 \mathrm{mg}, 0.9 \mathrm{mM}), 5 \mu \mathrm{L}(0.5 \mathrm{mg}, 4.3 \mathrm{mM}), 10 \mu \mathrm{L}(1 \mathrm{mg}$, $8.5 \mathrm{mM}), 25 \mu \mathrm{L}(2.5 \mathrm{mg}, 21.1 \mathrm{mM}), 30 \mu \mathrm{L}(3 \mathrm{mg}, 25.3 \mathrm{mM}), 50 \mu \mathrm{L}$ $(5 \mathrm{mg}, 41.7 \mathrm{mM})$, and $100 \mu \mathrm{L}(10 \mathrm{mg}, 81.5 \mathrm{mM}))$ to the previous solution $(2 \mathrm{~mL})$ while the change in size was monitored by DLS. The same procedure was repeated with the divalent salt $\mathrm{CaCl}_{2}$. A stock solution was prepared where $\mathrm{CaCl}_{2}$ was dissolved in deionized water $(100 \mathrm{mg} / \mathrm{mL}, 901 \mathrm{mM})$. This solution was gradually added $(1 \mu \mathrm{L}$ (0.1 mg, $0.5 \mathrm{mM}), 5 \mu \mathrm{L}$ (0.5 mg, $2.2 \mathrm{mM}), 10 \mu \mathrm{L}$ ( $1 \mathrm{mg}, 4.5 \mathrm{mM}), 15$ $\mu \mathrm{L}(1.5 \mathrm{mg}, 6.7 \mathrm{mM})$, and $20 \mu \mathrm{L}(2 \mathrm{mg}, 8.9 \mathrm{mM}))$ to a fresh sample of the previous solution $(2 \mathrm{~mL})$ while the change in size was monitored by DLS.

\section{Study of the Effect of macro-CTA Concentration on Styrene Nanoemulsion by Simple Shaking}

macro-CTA $(12.5,25$, or $50 \mathrm{mg}$; $0.0014,0.0028,0.0056 \mathrm{mmol})$ was placed in a $2 \mathrm{~mL}$ glass vial and was dissolved with an aqueous solution of SDS ( $0.25 \mathrm{mg}$ of SDS in $2 \mathrm{~mL}$ of deionized water, $0.0009 \mathrm{mmol}$ ). Then, styrene $(35 \mu \mathrm{L}, 0.3045 \mathrm{mmol})$ was added on the top of the SDS and macro-CTA solution. The vial was capped and shaken by hand for $10 \mathrm{~s}$. The resulting latexes were analyzed by DLS to determine the particle size and polydispersity.

\section{Study of the Effect of SDS Concentration on Styrene} Nanoemulsion by Simple Shaking

macro-CTA ( $25 \mathrm{mg}, 0.0028 \mathrm{mmol})$ was placed in a $2 \mathrm{~mL}$ glass vial. A stock solution of SDS in water was prepared $(16 \mathrm{mg}$ in $8 \mathrm{~mL}$ of deionized water), and various amounts were placed in the $2 \mathrm{~mL}$ vial ( $2 \mathrm{~mL}$ (4 mg, $6.94 \mathrm{mM}), 1.25 \mathrm{~mL}$ (2.5 mg, $4.34 \mathrm{mM}), 500 \mu \mathrm{L}(1 \mathrm{mg}$, $1.74 \mathrm{mM}), 250 \mu \mathrm{L}(0.5 \mathrm{mg}, 0.87 \mathrm{mM}), 125 \mu \mathrm{L}(0.25 \mathrm{mg}, 0.43 \mathrm{mM})$, $12.5 \mu \mathrm{L}(0.025 \mathrm{mg}, 0.04 \mathrm{mM})$, and $0.125 \mu \mathrm{L}(0.0025 \mathrm{mg}, 0.004$ $\mathrm{mM})$ ). A complementary amount of water was added to reach a final volume of $2 \mathrm{~mL}$ of water for each vial. Then, styrene $(35 \mu \mathrm{L}, 0.3045$ mmol) was added on the top of the SDS and macro-CTA solution. The vial was capped and shaken by hand for $10 \mathrm{~s}$. The resulting latexes were analyzed by DLS to determine the particle size and polydispersity.

\section{Kinetic Study of RAFT Nanoemulsion Polymerization of} Styrene

macro-CTA ( $25 \mathrm{mg}, 0.0028 \mathrm{mmol}, 1$ equiv) was placed in a $2 \mathrm{~mL}$ glass vial and was dissolved with an aqueous solution of SDS $(0.25 \mathrm{mg}$ of SDS in $2 \mathrm{~mL}$ of deionized water, $0.0009 \mathrm{mmol}, 0.3$ equiv). In parallel, a stock solution was prepared containing $2 \mathrm{mg}$ of AIBN dissolved in $1166 \mu \mathrm{L}$ of styrene. From this stock solution, $35 \mu \mathrm{L}$ (AIBN, $0.06 \mathrm{mg}, 0.0004 \mathrm{mmol}, 0.1$ equiv; styrene, $0.3045 \mathrm{mmol}, 108$ equiv) was transferred on the top of the SDS and macro-CTA solution. The vial was closed with a cap and shaken for $10 \mathrm{~s}$ by hand at room temperature. Then, the sample was analyzed by DLS at 70 ${ }^{\circ} \mathrm{C}$, to confirm the particle size at time 0 before polymerization. This procedure was repeated six more times in order to obtain a total of six vials. Those six vials were place in a preheated oven $\left(70{ }^{\circ} \mathrm{C}\right)$ at the same time, and one vial was taken out of the oven every $1 \mathrm{~h}$. Polymerization was stopped by exposing the latex to air. Aliquots of the latex were analyzed by ${ }^{1} \mathrm{H}$ NMR and SEC to determine the conversion, molecular weight, and dispersity. The conversion was calculated by the integral area of a peak at $5.8 \mathrm{ppm}\left(I_{5.8}\right)$ and a peak in the range 6.5-7.7 ppm $\left(I_{6.5-7.7}\right)$ using the following equation: conversion of styrene $=100\left(1-\left[5 I_{5.8} /\left(I_{6.5-7.7}-I_{5.8}\right)\right]\right)$. In parallel, the hot latex $\left(70^{\circ} \mathrm{C}\right)$ was analyzed by DLS and TEM to determine the particle size and polydispersity. 
RAFT (Nano)emulsion Polymerization of Styrene without SDS

macro-CTA (25 mg, $0.0028 \mathrm{mmol}, 1$ equiv) was placed in a $2 \mathrm{~mL}$ glass vial and was dissolved in deionized water $(2 \mathrm{~mL})$. In parallel, a stock solution was prepared containing $2 \mathrm{mg}$ of AIBN dissolved in $1166 \mu \mathrm{L}$ of styrene. From this stock solution, $35 \mu \mathrm{L}$ (AIBN, $0.06 \mathrm{mg}$, $0.0004 \mathrm{mmol}, 0.1$ equiv; styrene, $0.3045 \mathrm{mmol}, 108$ equiv) was transferred on the top of the macro-CTA solution. The vial was closed with a cap, shaken for $10 \mathrm{~s}$ by hand at room temperature, and placed in a preheated oven $\left(70{ }^{\circ} \mathrm{C}\right)$ for $6 \mathrm{~h}$. Aliquots of the latex were analyzed by SEC and DLS to determine the molecular weight, dispersity, size, and polydispersity.

\section{Scale-up of RAFT Nanoemulsion Polymerization of Styrene $(20 \mathrm{~mL})$}

macro-CTA ( $250 \mathrm{mg}, 0.028 \mathrm{mmol}, 1$ equiv) was placed in a $20 \mathrm{~mL}$ glass vial with an aqueous solution of SDS $(2.5 \mathrm{mg}$ of SDS in $20 \mathrm{~mL}$ of deionized water, $0.009 \mathrm{mmol}, 0.3$ equiv). In parallel, a stock solution was prepared containing $2 \mathrm{mg}$ of AIBN dissolved in $1166 \mu \mathrm{L}$ of styrene. From this stock solution, $350 \mu \mathrm{L}$ (AIBN, $0.6 \mathrm{mg}, 0.004$ mmol, 0.1 equiv; styrene, $3.045 \mathrm{mmol}, 108$ equiv) was transferred on the top of the macro-CTA solution. The vial was closed with a cap, shaken for $10 \mathrm{~s}$ by hand at room temperature, and placed in a preheated oven $\left(70^{\circ} \mathrm{C}\right)$ for $6 \mathrm{~h}$. Aliquots of the latex were analyzed by SEC, TEM, and DLS to determine the shape, size and polydispersity. RAFT Nanoemulsion Polymerization of Styrene with One-Sixth, One-Third, and Half of Headspace

macro-CTA (50 mg, $0.0056 \mathrm{mmol}, 1$ equiv) was placed in a $4 \mathrm{~mL}$ glass vial and was dissolved with an aqueous solution of SDS $(0.50 \mathrm{mg}$ of SDS in $4 \mathrm{~mL}$ of deionized water, $0.0018 \mathrm{mmol}, 0.3$ equiv). In parallel, a stock solution was prepared containing $2 \mathrm{mg}$ of AIBN dissolved in $1166 \mu \mathrm{L}$ of styrene. From this stock solution, $70 \mu \mathrm{L}$ (AIBN, $0.12 \mathrm{mg}, 0.0008 \mathrm{mmol}, 0.1$ equiv; styrene, $0.6090 \mathrm{mmol}, 108$ equiv) was transferred on the top of the SDS and macro-CTA solution. The vial was closed with a cap and shaken for $10 \mathrm{~s}$ by hand at room temperature. Then, the solution was split into three different $2 \mathrm{~mL}$ vials (1.68 mL (one-sixth of headspace), $1.34 \mathrm{~mL}$ (one-third of headspace), and $1 \mathrm{~mL}$ (half of headspace)) and closed with a cap. Those six vials were placed in a preheated oven $\left(70{ }^{\circ} \mathrm{C}\right)$ for $6 \mathrm{~h}$. Polymerization was stopped by exposing the latex to air. Aliquots of the latex were analyzed by SEC to determine the molecular weight and dispersity.

\section{RAFT Polymerization of Styrene without a Preformed Nanoemulsion}

macro-CTA ( $25 \mathrm{mg}, 0.0028 \mathrm{mmol}, 1$ equiv) was placed in a $2 \mathrm{~mL}$ glass vial and was dissolved with an aqueous solution of SDS $(0.25 \mathrm{mg}$ of SDS in $2 \mathrm{~mL}$ of deionized water, $0.0009 \mathrm{mmol}, 0.3$ equiv). In parallel, a stock solution was prepared containing $2 \mathrm{mg}$ of AIBN dissolved in $1166 \mu \mathrm{L}$ of styrene. From this stock solution, $35 \mu \mathrm{L}$ (AIBN, $0.06 \mathrm{mg}, 0.0004 \mathrm{mmol}, 0.1$ equiv; styrene, $0.3045 \mathrm{mmol}, 108$ equiv) was transferred on the top of the SDS and macro-CTA solution. Without shaking (the solution was transparent and the styrene phase was on the top), the vial was closed with a cap and placed in a preheated oven $\left(70{ }^{\circ} \mathrm{C}\right)$. After $6 \mathrm{~h}$, polymerization was stopped by exposing the solution to air and the solution analyzed by SEC to determine the molecular weight and dispersity.

RAFT Polymerization of Styrene Undertaken without a Preformed Nanoemulsion and with Stirring in a Preheated Oil Bath

macro-CTA ( $25 \mathrm{mg}, 0.0028 \mathrm{mmol}, 1$ equiv) was placed in a $2 \mathrm{~mL}$ glass vial, equipped with a stirring bar, and was dissolved with an aqueous solution of SDS ( $0.25 \mathrm{mg}$ of SDS in $2 \mathrm{~mL}$ of deionized water, $0.0009 \mathrm{mmol}, 0.3$ equiv). In parallel, a stock solution was prepared containing $2 \mathrm{mg}$ of AIBN dissolved in $1166 \mu \mathrm{L}$ of styrene. From this stock solution, $35 \mu \mathrm{L}$ (AIBN, $0.06 \mathrm{mg}, 0.0004 \mathrm{mmol}, 0.1$ equiv; styrene, $0.3045 \mathrm{mmol}, 108$ equiv) was transferred on the top of the SDS and macro-CTA solution. Without shaking (the solution was transparent), the vial was closed with a cap and place in a preheated oil bath $\left(70{ }^{\circ} \mathrm{C}\right)$ with stirring at $300 \mathrm{rpm}$. After $6 \mathrm{~h}$, polymerization was stopped by exposing the latex to air and the sample was analyzed by SEC to determine the molecular weight and dispersity. The hot latex $\left(70^{\circ} \mathrm{C}\right)$ was also analyzed by DLS to determine the particle size and polydispersity.

Synthesis of Nanoparticles with Different Morphologies

by RAFT Nanoemulsion Polymerization of Styrene

macro-CTA ( $25 \mathrm{mg}, 0.0028 \mathrm{mmol}, 1$ equiv) was placed in a $2 \mathrm{~mL}$ glass vial and was dissolved with an aqueous solution of SDS $(0.25 \mathrm{mg}$ of SDS in $2 \mathrm{~mL}$ of deionized water, $0.0009 \mathrm{mmol}, 0.3$ equiv). In parallel, a stock solution was prepared containing $2 \mathrm{mg}$ of AIBN dissolved in $1166 \mu \mathrm{L}$ of styrene. From this stock solution, $35 \mu \mathrm{L}$ (AIBN, $0.06 \mathrm{mg}, 0.0004 \mathrm{mmol}, 0.1$ equiv; styrene, $0.3045 \mathrm{mmol}, 108$ equiv, B3) was transferred on the top of the SDS and macro-CTA solution. The vial was closed with a cap and shaken for $10 \mathrm{~s}$ by hand. After $6 \mathrm{~h}$, polymerization was stopped by exposing the latex to air and the sample analyzed by SEC to determine the molecular weight and dispersity. Subsequently, $400 \mu \mathrm{L}$ of warm latex $\left(70{ }^{\circ} \mathrm{C}\right)$ was transferred into four $1.5 \mathrm{~mL}$ vials $(100 \mu \mathrm{L}$ per vial). Each vial contained a different amount of toluene $(0.1,0.5,0.8$, or $10 \mu \mathrm{L})$. The vials were then placed on the bench to cool the latexes to room temperature. After $24 \mathrm{~h}$, the latexes were analyzed by TEM. To vary the DP and obtain B1 and B2 block copolymers, the same procedure was followed and the amount of styrene was adjusted to $7 \mu \mathrm{L}(0.0609$ mmol, 22 equiv) and $14 \mu \mathrm{L}(0.1218 \mathrm{mmol}, 43$ equiv), respectively, while the amount of AIBN was kept constant at $0.06 \mathrm{mg}(0.0004$ mmol, 0.1 equiv).

Synthesis of Nanoparticles by RAFT Nanoemulsion Polymerization of Styrene with In Situ Morphology Transformation

macro-CTA ( $25 \mathrm{mg}, 0.0028 \mathrm{mmol}, 1$ equiv) was placed in a $2 \mathrm{~mL}$ glass vial and was dissolved with an aqueous solution of SDS $(0.25 \mathrm{mg}$ of SDS in $2 \mathrm{~mL}$ of deionized water, $0.0009 \mathrm{mmol}, 0.3$ equiv). In parallel, a stock solution was prepared containing $3.75 \mathrm{mg}$ of AIBN dissolved in $1000 \mu \mathrm{L}$ of styrene. From this stock solution, $16 \mu \mathrm{L}$ (AIBN, $0.06 \mathrm{mg}, 0.0004 \mathrm{mmol}, 0.1$ equiv; styrene, $0.139 \mathrm{mmol}, 50$ equiv) was transferred on the top of the SDS and macro-CTA solution. The vial was closed with a cap and shaken for $10 \mathrm{~s}$ by hand. After $4 \mathrm{~h}$, polymerization was stopped by opening the vial to air and the sample analyzed by SEC to determine the molecular weight and dispersity. The vial was capped again and cooled to room temperature. The capped vial was left overnight on the bench and was then analyzed by TEM to determine the resulting morphology. This procedure was repeated two times, for $5 \mathrm{~h}$, by transferring $16 \mu \mathrm{L}$ of the styrene stock solution with an additional $4 \mu \mathrm{L}$ of styrene (AIBN, $0.06 \mathrm{mg}, 0.0004 \mathrm{mmol}, 0.1$ equiv; styrene, $0.174 \mathrm{mmol}, 61$ equiv) and with an additional $69 \mu \mathrm{L}$ of styrene (AIBN, $0.06 \mathrm{mg}$, $0.0004 \mathrm{mmol}, 0.1$ equiv; styrene, $0.739 \mathrm{mmol}, 263$ equiv) on top of the SDS and macro-CTA solution in two distinct vials.

\section{Study of Worm Degradation by Sonication}

Nanoworms obtained with polymers B2 were dissolved in water (10 $\mu \mathrm{L}$ in $1 \mathrm{~mL}$ of deionized water) and sonicated for $15 \mathrm{~min}, 30 \mathrm{~min}$ and $1 \mathrm{~h}$. The resulting samples were, each time, observed with TEM to determine the nanoworm degradation.

Synthesis of Nanoparticles with Different Shapes by RAFT Nanoemulsion Polymerization of Methyl Methacrylate

macro-CTA (40 mg, $0.0045 \mathrm{mmol}, 1$ equiv) was placed in a $2 \mathrm{~mL}$ glass vial and was dissolved with an aqueous solution of SDS $(0.50 \mathrm{mg}$ of SDS in $2 \mathrm{~mL}$ of deionized water, $0.0017 \mathrm{mmol}, 0.4$ equiv). In parallel, a stock solution was prepared containing $2 \mathrm{mg}$ of AIBN dissolved in $1666 \mu \mathrm{L}$ of MMA. From this stock solution, $50 \mu \mathrm{L}$ (AIBN, $0.06 \mathrm{mg}, 0.0004 \mathrm{mmol}, 0.1$ equiv; MMA, $0.4349 \mathrm{mmol}, 100$ equiv) was transferred on the top of the SDS and macro-CTA solution. The vial was closed with a cap, shaken for $10 \mathrm{~s}$ by hand, and place in a preheated oven $\left(70^{\circ} \mathrm{C}\right)$ for $2 \mathrm{~h}(\mathrm{~B} 4), 2 \mathrm{~h} 15 \mathrm{~min}(\mathrm{~B} 5)$, and $2 \mathrm{~h} 20 \mathrm{~min}$ (B6). The polymerization was stopped by exposing the latex to air at $70^{\circ} \mathrm{C}$, and the vial was bubbled with air for $7 \mathrm{~min}$ at 70 
${ }^{\circ} \mathrm{C}$ to remove the remaining monomer. The solution was analyzed by SEC to determine the molecular weight and dispersity. Subsequently, $400 \mu \mathrm{L}$ of warm latex $\left(70{ }^{\circ} \mathrm{C}\right)$ was transferred into four $1.5 \mathrm{~mL}$ vials (100 $\mu \mathrm{L}$ per vial). Each vial contained a different amount of MMA $(0.25,0.5,1$, or $10 \mu \mathrm{L})$. The vials were then placed on the bench to cool the latexes to room temperature. After $24 \mathrm{~h}$, the latexes were stained and analyzed by TEM.

\section{Synthesis of Ethyl Acrylate by RAFT Nanoemulsion Polymerization}

macro-CTA ( $80 \mathrm{mg}, 0.0089 \mathrm{mmol}, 1$ equiv) was placed in a $2 \mathrm{~mL}$ glass vial and was dissolved with an aqueous solution of SDS (1 mg of SDS in $2 \mathrm{~mL}$ of deionized water, $0.0035 \mathrm{mmol}, 0.4$ equiv). In parallel, a stock solution was prepared containing $2 \mathrm{mg}$ of AIBN dissolved in $1000 \mu \mathrm{L}$ of EA. From this stock solution, $50 \mu \mathrm{L}$ (AIBN, $1 \mathrm{mg}, 0.0006$ mmol, 0.1 equiv; EA, $0.452 \mathrm{mmol}, 50$ equiv) was transferred on the top of the SDS and macro-CTA solution. The vial was closed with a cap, shaken for $10 \mathrm{~s}$ by hand, analyzed by DLS, and places in a preheated oven $\left(70{ }^{\circ} \mathrm{C}\right)$ for $5 \mathrm{~h}$. The polymerization was stopped by exposing the latex to air at $70{ }^{\circ} \mathrm{C}$. The solution was analyzed by SEC to determine the molecular weight and dispersity.

\section{ASSOCIATED CONTENT}

\section{Supporting Information}

The Supporting Information is available free of charge at https://pubs.acs.org/doi/10.1021/jacsau.1c00321.

Material information, instrumentation, and additional figures and tables as described in the text (PDF) Video illustrating manual shaking (MP4)

\section{AUTHOR INFORMATION}

\section{Corresponding Author}

Athina Anastasaki - Laboratory for Polymeric Materials, Department of Materials, ETH Zürich, 8093 Zürich, Switzerland; ๑ orcid.org/0000-0002-6615-1026;

Email: athina.anastasaki@mat.ethz.ch

\section{Authors}

Manon Rolland - Laboratory for Polymeric Materials, Department of Materials, ETH Zürich, 8093 Zürich, Switzerland; 이이이.org/0000-0001-8975-3794

Nghia P. Truong - Laboratory for Polymeric Materials, Department of Materials, ETH Zürich, 8093 Zürich, Switzerland; Monash Institute of Pharmaceutical Sciences, Monash University, Parkville, Victoria 3052, Australia; (1) orcid.org/0000-0001-9900-2644

Kostas Parkatzidis - Laboratory for Polymeric Materials, Department of Materials, ETH Zürich, 8093 Zürich, Switzerland

Emily H. Pilkington - Monash Institute of Pharmaceutical Sciences, Monash University, Parkville, Victoria 3052, Australia

Alexandre L. Torzynski - Laboratory of Soft and Living Materials, Department of Materials, ETH Zürich, 8093 Zürich, Switzerland

Robert W. Style - Laboratory of Soft and Living Materials, Department of Materials, ETH Zürich, 8093 Zürich, Switzerland; 이이이.org/0000-0001-5305-7658

Eric R. Dufresne - Laboratory of Soft and Living Materials, Department of Materials, ETH Zürich, 8093 Zürich, Switzerland; ㅇo이.org/0000-0002-3091-5039

Complete contact information is available at: https://pubs.acs.org/10.1021/jacsau.1c00321

\section{Author Contributions}

${ }^{\|}$M.R. and N.P.T. contributed equally.

Notes

The authors declare no competing financial interest.

\section{ACKNOWLEDGMENTS}

A.A. gratefully acknowledges ETH Zurich for financial support. N.P.T. acknowledges the award of a DECRA Fellowship and DP from the ARC (DE180100076 and DP200100231). K.P. thanks the Onassis Foundation, as this scientific paper was supported by the Onassis Foundation - Scholarship ID: FZQ051-1/2020-2021. We are grateful to ScopeM (ETH Zürich) and Monash Centre for Electron Microscopy, a Node of Microscopy Australia, for access to the electron microscopy facilities. We thank Prof. Isa Lucio and the group members of the Laboratory for Soft Materials and Interfaces for access to dynamic light scattering (DLS).

\section{REFERENCES}

(1) Hashemnejad, S. M.; Badruddoza, A. Z. M.; Zarket, B.; Castaneda, C. R.; Doyle, P. S. Thermoresponsive nanoemulsionbased gel synthesized through a low-energy process. Nat. Commun. 2019, 10, 2749.

(2) Gupta, A.; Eral, H. B.; Hatton, T. A.; Doyle, P. S. Nanoemulsions: formation, properties and applications. Soft Matter 2016, 12, 2826-2841.

(3) Maali, A.; Mosavian, M. H. Preparation and application of nanoemulsions in the last decade (2000-2010). J. Dispersion Sci. Technol. 2013, 34, 92-105.

(4) Singh, Y.; Meher, J. G.; Raval, K.; Khan, F. A.; Chaurasia, M.; Jain, N. K.; Chourasia, M. K. Nanoemulsion: Concepts, development and applications in drug delivery. J. Controlled Release 2017, 252, 2849.

(5) Wang, L.; Dong, J.; Chen, J.; Eastoe, J.; Li, X. Design and optimization of a new self-nanoemulsifying drug delivery system. $J$. Colloid Interface Sci. 2009, 330, 443-448.

(6) Shah, P.; Bhalodia, D.; Shelat, P. Nanoemulsion: a pharmaceutical review. Syst. Rev. Pharm. 2010, 1, 24.

(7) Cheng, C. J.; Tietjen, G. T.; Saucier-Sawyer, J. K.; Saltzman, W. M. A holistic approach to targeting disease with polymeric nanoparticles. Nat. Rev. Drug Discovery 2015, 14, 239-247.

(8) Fytianos, G.; Rahdar, A.; Kyzas, G. Z. Nanomaterials in cosmetics: Recent updates. Nanomaterials 2020, 10, 979.

(9) Wu, X.; Guy, R. H. Applications of nanoparticles in topical drug delivery and in cosmetics. J. Drug Delivery Sci. Technol. 2009, 19, 371384.

(10) Sanguansri, P.; Augustin, M. A. Nanoscale materials development-a food industry perspective. Trends Food Sci. Technol. 2006, 17, 547-556.

(11) Rao, J.; McClements, D. J. Stabilization of phase inversion temperature nanoemulsions by surfactant displacement. J. Agric. Food Chem. 2010, 58, 7059-7066.

(12) Fryd, M. M.; Mason, T. G. Advanced nanoemulsions. Annu. Rev. Phys. Chem. 2012, 63, 493-518.

(13) Wang, Y.; Fu, L.; Matyjaszewski, K. Enzyme-deoxygenated low parts per million atom transfer radical polymerization in miniemulsion and ab initio emulsion. ACS Macro Lett. 2018, 7, 1317-1321.

(14) Min, K.; Gao, H.; Matyjaszewski, K. Preparation of homopolymers and block copolymers in miniemulsion by ATRP using activators generated by electron transfer (AGET). J. Am. Chem. Soc. 2005, 127, 3825-3830.

(15) Qiu, J.; Charleux, B.; Matyjaszewski, K. Controlled/living radical polymerization in aqueous media: homogeneous and heterogeneous systems. Prog. Polym. Sci. 2001, 26, 2083-2134. 
(16) Gurnani, P.; Perrier, S. Controlled radical polymerization in dispersed systems for biological applications. Prog. Polym. Sci. 2020, 102, 101209.

(17) Wang, Y.; Dadashi-Silab, S.; Matyjaszewski, K. Photoinduced miniemulsion atom transfer radical polymerization. ACS Macro Lett. 2018, 7, 720-725.

(18) Oliveira, M. A. M.; Boyer, C.; Nele, M.; Pinto, J. C.; Zetterlund, P. B.; Davis, T. P. Synthesis of biodegradable hydrogel nanoparticles for bioapplications using inverse miniemulsion RAFT polymerization. Macromolecules 2011, 44, 7167-7175.

(19) An, Z.; Shi, Q.; Tang, W.; Tsung, C.-K.; Hawker, C. J.; Stucky, G. D. Facile RAFT precipitation polymerization for the microwaveassisted synthesis of well-defined, double hydrophilic block copolymers and nanostructured hydrogels. J. Am. Chem. Soc. 2007, 129, 14493-14499.

(20) Zetterlund, P. B. Controlled/living radical polymerization in nanoreactors: compartmentalization effects. Polym. Chem. 2011, 2, 534-549.

(21) Truong, N. P.; Dussert, M. V.; Whittaker, M. R.; Quinn, J. F.; Davis, T. P. Rapid synthesis of ultrahigh molecular weight and low polydispersity polystyrene diblock copolymers by RAFT-mediated emulsion polymerization. Polym. Chem. 2015, 6, 3865-3874.

(22) Frisch, H.; Menzel, J. P.; Bloesser, F. R.; Marschner, D. E.; Mundsinger, K.; Barner-Kowollik, C. Photochemistry in confined environments for single-chain nanoparticle design. J. Am. Chem. Soc. 2018, 140, 9551-9557.

(23) Zetterlund, P. B.; Thickett, S. C.; Perrier, S.; Bourgeat-Lami, E.; Lansalot, M. Controlled/living radical polymerization in dispersed systems: an update. Chem. Rev. 2015, 115, 9745-9800.

(24) Pham, B. T.; Nguyen, D.; Ferguson, C. J.; Hawkett, B. S.; Serelis, A. K.; Such, C. H. Miniemulsion polymerization stabilized by amphipathic macro RAFT agents. Macromolecules 2003, 36, 89078909.

(25) Minami, H.; Shimomura, K.; Suzuki, T.; Sakashita, K.; Noda, T. RAFT Polymerization in a Miniemulsion System Using a Novel Type of Amphiphilic RAFT Agent with Poly (ethylene glycol) Bound to a Dithiobenzoate Group. Macromolecules 2014, 47, 130-136.

(26) Oh, J. K.; Tang, C.; Gao, H.; Tsarevsky, N. V.; Matyjaszewski, $\mathrm{K}$. Inverse miniemulsion ATRP: a new method for synthesis and functionalization of well-defined water-soluble/cross-linked polymeric particles. J. Am. Chem. Soc. 2006, 128, 5578-5584.

(27) Li, W.; Matyjaszewski, K.; Albrecht, K.; Möller, M. Reactive surfactants for polymeric nanocapsules via interfacially confined miniemulsion ATRP. Macromolecules 2009, 42, 8228-8233.

(28) Khor, S. Y.; Quinn, J. F.; Whittaker, M. R.; Truong, N. P.; Davis, T. P. Controlling Nanomaterial Size and Shape for Biomedical Applications via Polymerization-Induced Self-Assembly. Macromol. Rapid Commun. 2019, 40, 1800438.

(29) Kaga, S.; Truong, N. P.; Esser, L.; Senyschyn, D.; Sanyal, A.; Sanyal, R.; Quinn, J. F.; Davis, T. P.; Kaminskas, L. M.; Whittaker, M. $\mathrm{R}$. Influence of size and shape on the biodistribution of nanoparticles prepared by polymerization-induced self-assembly. Biomacromolecules 2017, 18, 3963-3970.

(30) Truong, N. P.; Quinn, J. F.; Whittaker, M. R.; Davis, T. P. Polymeric filomicelles and nanoworms: two decades of synthesis and application. Polym. Chem. 2016, 7, 4295-4312.

(31) Discher, B. M.; Won, Y.-Y.; Ege, D. S.; Lee, J. C.; Bates, F. S.; Discher, D. E.; Hammer, D. A. Polymersomes: tough vesicles made from diblock copolymers. Science 1999, 284, 1143-1146.

(32) Truong, N. P.; Quinn, J. F.; Dussert, M. V.; Sousa, N. B.; Whittaker, M. R.; Davis, T. P. Reproducible access to tunable morphologies via the self-assembly of an amphiphilic diblock copolymer in water. ACS Macro Lett. 2015, 4, 381-386.

(33) Boursier, T.; Chaduc, I.; Rieger, J.; d'Agosto, F.; Lansalot, M.; Charleux, B. Controlled radical polymerization of styrene in miniemulsion mediated by PEO-based trithiocarbonate macromolecular RAFT agents. Polym. Chem. 2011, 2, 355-362.
(34) Luo, Y.; Gu, H. A General Strategy for Nano-Encapsulation via Interfacially Confined Living/Controlled Radical Miniemulsion Polymerization. Macromol. Rapid Commun. 2006, 27, 21-25.

(35) Tadros, T.; Izquierdo, P.; Esquena, J.; Solans, C. Formation and stability of nano-emulsions. Adv. Colloid Interface Sci. 2004, 108, 303318.

(36) Solans, C.; Solé, I. Nano-emulsions: formation by low-energy methods. Curr. Opin. Colloid Interface Sci. 2012, 17, 246-254.

(37) Forgiarini, A.; Esquena, J.; Gonzalez, C.; Solans, C. Formation of nano-emulsions by low-energy emulsification methods at constant temperature. Langmuir 2001, 17, 2076-2083.

(38) Lin, T. Effects of phase inversion and surfactant location on the formation of O/W emulsions. J. Soc. Cosmet. Chem. 1975, 26, 121139.

(39) Feng, J.; Rodríguez-Abreu, C.; Esquena, J.; Solans, C. A Concise Review on Nano-emulsion Formation by the Phase Inversion Composition (PIC) Method. J. Surfactants Deterg. 2020, 23, 677685.

(40) Shinoda, K.; Saito, H. The stability of O/W type emulsions as functions of temperature and the HLB of emulsifiers: the emulsification by PIT-method. J. Colloid Interface Sci. 1969, 30, $258-263$.

(41) Solè, I.; Solans, C.; Maestro, A.; González, C.; Gutiérrez, J. Study of nano-emulsion formation by dilution of microemulsions. J. Colloid Interface Sci. 2012, 376, 133-139.

(42) Taylor, P.; Ottewill, R. The formation and ageing rates of oil-inwater miniemulsions. Colloids Surf., A 1994, 88, 303-316.

(43) Zhang, J.; Han, B.; Zhang, C.; Li, W.; Feng, X. Nanoemulsions induced by compressed gases. Angew. Chem., Int. Ed. 2008, 47, 30123015.

(44) Feng, J.; Roché, M.; Vigolo, D.; Arnaudov, L. N.; Stoyanov, S. D.; Gurkov, T. D.; Tsutsumanova, G. G.; Stone, H. A. Nanoemulsions obtained via bubble-bursting at a compound interface. Nat. Phys. 2014, 10, 606-612.

(45) Guo, Y.; Liu, J.; Zetterlund, P. B. Nitroxide-mediated radical polymerization in miniemulsion on the basis of in situ surfactant formation without use of homogenization device. Macromolecules 2010, 43, 5914-5916.

(46) Berry, J. D.; Neeson, M. J.; Dagastine, R. R.; Chan, D. Y.; Tabor, R. F. Measurement of surface and interfacial tension using pendant drop tensiometry. J. Colloid Interface Sci. 2015, 454, 226237.

(47) Domínguez, A.; Fernández, A.; González, N.; Iglesias, E.; Montenegro, L. Determination of critical micelle concentration of some surfactants by three techniques. J. Chem. Educ. 1997, 74, 1227.

(48) Ijavi, M.; Style, R. W.; Emmanouilidis, L.; Kumar, A.; Meier, S. M.; Torzynski, A. L.; Allain, F. H.; Barral, Y.; Steinmetz, M. O.; Dufresne, E. R. Surface tensiometry of phase separated protein and polymer droplets by the sessile drop method. Soft Matter 2021, 17, $1655-1662$.

(49) Truong, N. P.; Zhang, C.; Nguyen, T. A.; Anastasaki, A.; Schulze, M. W.; Quinn, J. F.; Whittaker, A. K.; Hawker, C. J.; Whittaker, M. R.; Davis, T. P. Overcoming surfactant-induced morphology instability of noncrosslinked diblock copolymer nanoobjects obtained by RAFT emulsion polymerization. ACS Macro Lett. 2018, 7, 159-165.

(50) Verwey, E. J. W.; Overbeek, J. T. G. Theory of the stability of lyophobic colloids. J. Colloid Sci. 1955, 10, 224-225.

(51) Shinoda, K.; Saito, H. The effect of temperature on the phase equilibria and the types of dispersions of the ternary system composed of water, cyclohexane, and nonionic surfactant. J. Colloid Interface Sci. 1968, 26, 70-74.

(52) Chiefari, J.; Chong, Y.; Ercole, F.; Krstina, J.; Jeffery, J.; Le, T. P.; Mayadunne, R. T.; Meijs, G. F.; Moad, C. L.; Moad, G.; et al. Living free-radical polymerization by reversible addition- fragmentation chain transfer: the RAFT process. Macromolecules 1998, 31, $5559-5562$. 
(53) Hill, M. R.; Carmean, R. N.; Sumerlin, B. S. Expanding the scope of RAFT polymerization: recent advances and new horizons. Macromolecules 2015, 48, 5459-5469.

(54) Barner, L.; Davis, T. P.; Stenzel, M. H.; Barner-Kowollik, C. Complex macromolecular architectures by reversible addition fragmentation chain transfer chemistry: theory and practice. Macromol. Rapid Commun. 2007, 28, 539-559.

(55) Moad, G.; Rizzardo, E.; Thang, S. H. Living radical polymerization by the RAFT process-a third update. Aust. J. Chem. 2012, 65, 985-1076.

(56) Moad, G.; Rizzardo, E.; Thang, S. H. RAFT polymerization and some of its applications. Chem. - Asian J. 2013, 8, 1634-1644.

(57) Nothling, M. D.; Fu, Q.; Reyhani, A.; Allison-Logan, S.; Jung, K.; Zhu, J.; Kamigaito, M.; Boyer, C.; Qiao, G. G. Progress and perspectives beyond traditional RAFT polymerization. Adv. Sci. 2020, 7, 2001656

(58) Vu, M. N.; Kelly, H. G.; Wheatley, A. K.; Peng, S.; Pilkington, E. H.; Veldhuis, N. A.; Davis, T. P.; Kent, S. J.; Truong, N. P. Cellular Interactions of Liposomes and PISA Nanoparticles during Human Blood Flow in a Microvascular Network. Small 2020, 16, 2002861.

(59) Boyer, C.; Bulmus, V.; Liu, J.; Davis, T. P.; Stenzel, M. H.; Barner-Kowollik, C. Well-defined protein- polymer conjugates via in situ RAFT polymerization. J. Am. Chem. Soc. 2007, 129, 7145-7154.

(60) Liarou, E.; Whitfield, R.; Anastasaki, A.; Engelis, N. G.; Jones, G. R.; Velonia, K.; Haddleton, D. M. Copper-Mediated Polymerization without External Deoxygenation or Oxygen Scavengers. Angew. Chem., Int. Ed. 2018, 57, 8998-9002.

(61) Liarou, E.; Anastasaki, A.; Whitfield, R.; Iacono, C. E.; Patias, G.; Engelis, N. G.; Marathianos, A.; Jones, G. R.; Haddleton, D. M. Ultra-low volume oxygen tolerant photoinduced Cu-RDRP. Polym. Chem. 2019, 10, 963-971.

(62) Rolland, M.; Whitfield, R.; Messmer, D.; Parkatzidis, K.; Truong, N. P.; Anastasaki, A. Effect of Polymerization Components on Oxygen-Tolerant Photo-ATRP. ACS Macro Lett. 2019, 8, 15461551.

(63) Theodorou, A.; Liarou, E.; Haddleton, D. M.; Stavrakaki, I. G.; Skordalidis, P.; Whitfield, R.; Anastasaki, A.; Velonia, K. Proteinpolymer bioconjugates via a versatile oxygen tolerant photoinduced controlled radical polymerization approach. Nat. Commun. 2020, 11, 1486.

(64) Szczepaniak, G.; Fu, L.; Jafari, H.; Kapil, K.; Matyjaszewski, K. Making ATRP More Practical: Oxygen Tolerance. Acc. Chem. Res. 2021, 54, 1779-1790.

(65) Layadi, A.; Kessel, B.; Yan, W.; Romio, M.; Spencer, N. D.; Zenobi-Wong, M.; Matyjaszewski, K.; Benetti, E. M. Oxygen Tolerant and Cytocompatible Iron (0)-Mediated ATRP Enables the Controlled Growth of Polymer Brushes from Mammalian Cell Cultures. J. Am. Chem. Soc. 2020, 142, 3158-3164.

(66) Blanazs, A.; Armes, S. P.; Ryan, A. J. Self-assembled block copolymer aggregates: from micelles to vesicles and their biological applications. Macromol. Rapid Commun. 2009, 30, 267-277.

(67) Hurst, P. J.; Rakowski, A. M.; Patterson, J. P. Ring-opening polymerization-induced crystallization-driven self-assembly of poly-Llactide-block-polyethylene glycol block copolymers (ROPI-CDSA). Nat. Commun. 2020, 11, 4690.

(68) Truong, N. P.; Quinn, J. F.; Anastasaki, A.; Haddleton, D. M.; Whittaker, M. R.; Davis, T. P. Facile access to thermoresponsive filomicelles with tuneable cores. Chem. Commun. 2016, 52, 44974500 .

(69) Truong, N. P.; Whittaker, M. R.; Anastasaki, A.; Haddleton, D. M.; Quinn, J. F.; Davis, T. P. Facile production of nanoaggregates with tuneable morphologies from thermoresponsive P (DEGMA-coHPMA). Polym. Chem. 2016, 7, 430-440.

(70) Khor, S. Y.; Truong, N. P.; Quinn, J. F.; Whittaker, M. R.; Davis, T. P. Polymerization-induced self-assembly: the effect of end group and initiator concentration on morphology of nanoparticles prepared via RAFT aqueous emulsion polymerization. ACS Macro Lett. 2017, 6, 1013-1019. 


\section{University Library}

\section{- M M N E R VA A gateway to Melbourne's research publications}

Minerva Access is the Institutional Repository of The University of Melbourne

\section{Author/s:}

Rolland, M;Truong, NP;Parkatzidis, K;Pilkington, EH;Torzynski, AL;Style, RW;Dufresne, ER;Anastasaki, A

Title:

Shape-Controlled Nanoparticles from a Low-Energy Nanoemulsion.

\section{Date:}

2021-11-22

\section{Citation:}

Rolland, M., Truong, N. P., Parkatzidis, K., Pilkington, E. H., Torzynski, A. L., Style, R. W., Dufresne, E. R. \& Anastasaki, A. (2021). Shape-Controlled Nanoparticles from a Low-Energy Nanoemulsion.. JACS Au, 1 (11), pp.1975-1986. https://doi.org/10.1021/jacsau.1c00321.

Persistent Link:

http://hdl.handle.net/11343/296196

License:

CC BY-NC-ND 